\title{
How can the recall of early affiliative memories with peers influence on disordered eating behaviours?
}

\author{
Ana Laura Mendes, Joana Marta-Simões and Cláudia Ferreira \\ Universidade de Coimbra (Portugal)
}

Correspondence concerning this article should be addressed to:

Ana Laura Mendes, University of Coimbra- Faculty of Psychology and Educational Sciences, Rua do Colégio Novo, Apartado 6153, 3001-802. Coimbra (Portugal)

E-mail: analauramendes@live.com.pt

Phone: (+351)239851450; (+351)203851462 


\section{Abstract}

The present study aimed to explore the role of early affiliative memories with peers on the adoption of disordered eating attitudes and behaviours through the mechanisms of external shame and self-judgment. The sample used in the current study comprised 632 women from the community, aged between 18 and 60 years old.

The tested model explained $22 \%$ of eating psychopathology's variance and showed excellent model fit indices. Results indicated that the impact of the recall of early positive memories with peers on eating psychopathology was fully carried through the mechanisms of external shame and self-judgment. In fact, these findings seem to suggest that the lack of warm and safe affiliative memories with peers is linked with higher levels of shame (e.g., feelings of inferiority and inadequacy), and also with higher vulnerability to engage in maladaptive emotional strategies (such as self-judgmental attitudes), which appears to explain the increase of disordered eating behaviours.

These findings contribute to the understanding of the impact of peer-related early affiliative memories on the engagement in disordered eating. Furthermore, this study has significant clinical implications, emphasizing the importance of targeting shame and maladaptive emotional strategies, especially in a context involving early adverse emotional experiences with peers.

Keywords: Early affiliative memories, peer relationships, external shame, self-judgment, eating psychopathology. 


\section{Introduction}

It is widely accepted that affiliative relationships are crucial to our survival and physical and psychological well-being [e.g., 1-3]. In fact, literature has consistently demonstrated that early affiliative experiences, either positive or negative, seem to play an important role on physiological, psychological and social aspects of human development and functioning [4-6].

Several studies suggest that early experiences of warmth, safeness, soothing and care are associated with positive feelings, self-esteem, happiness, and emotional health [7-9]. On the other hand, early experiences characterized by rejection, abuse, neglect and shame are linked to worse mental health outcomes and higher vulnerability to psychopathology [e.g., 10].

Furthermore, several authors have highlighted that early affiliative experiences can be registered as autobiographic memories [11], with influence on emotion regulation, self-identity [12] and on the development of the relational schema (self-self and self-others; [13-16]). In this line, early positive memories are associated with the development of adaptive emotion processes, which enhance the ability to cope with stressful events and demanding contexts [e.g., 17]. Also, the recall of negative emotional and relational memories seems to play a central role in the construction of self-identity and life story [14, 18], operating as threat-activating memories that function like emotional hot-spots, highly available in the mind [e.g., 19].

To sum up, while warm, supportive and safe environments promote feelings of social safeness, affiliation and connectedness, facilitating the adaptive coping with personal failures and setbacks [e.g., 20], negative relational and emotional experiences can activate the threat system, which is associated with feelings of insecurity, such as shame, and potentially harmful defensive behaviours [21, 22].

Shame is conceptualized as a multifaceted self-conscious emotion of outstanding social importance $[19,23]$, which plays a key role on self-identity [e.g., 19]. This powerful emotion emerges in social contexts through one's perception of existing negatively in the minds of 
others (e.g., as inferior, undesirable, inadequate, defective or unattractive; [e.g., 13, 24]). Furthermore, this painful emotion can be internalized, leading to one's perception of the self as inferior, flawed or inadequate $[13,23,25]$. Literature has consistently linked high levels of shame to psychosocial impairment and a wide range of psychopathological conditions [e.g., $23,26]$, namely eating disorders [27-30]. In fact, shame may trigger a series of defensive responses (aiming to correct features or attitudes perceived as defective), such as self-directed negative affect and self-judgmental attitudes [31].

Self-judgment, a maladaptive emotion regulation strategy, is defined as a harshly critical and judgmental attitude towards the self, which involves feelings of isolation, over identification with one's own negative feelings, thoughts and emotional states, and selfattribution of errors and adverse life experiences [32]. However, the detrimental effect underlying self-judgment goes beyond the content of the criticism. Actually, the main harmful aspect of this judgmental attitude is the self-directed negative affect. In this way, high levels of self-judgment are associated with a decreased capacity of being self-compassionate [e.g., 32]. In fact, being harshly self-critical and judgmental seems to be associated with lower well-being and also to higher vulnerability to psychopathology, namely eating disorders [27, 30].

To sum up, there is consistent evidence of the central role of shame and maladaptive emotional processes (such as self-judgment) on eating psychopathology [e.g., 30, 33]. Also, recent data shed light on the role of early relational experiences, such as weight-related teasing and bullying, in the proneness to disordered eating attitudes and behaviours [34, 35]. However, the impact of early peer-related affiliative memories on eating psychopathology remains scarcely investigated.

The present study aimed to explore the impact of the recall of peer-related early affiliative memories on the engagement in disordered eating attitudes and behaviours, and whether external shame and self-judgmental attitudes significantly act on this association. In accordance 
with previous research, eating psychopathology symptoms may be conceptualized as means to compete in the social world and avoid shame and the sense of inferiority [30, 36]. In this line, it was hypothesized that the scarcity of early positive memories with peers may be associated with higher levels of eating psychopathology, through the mechanisms of external shame and self-judgment.

\section{Materials and Methods}

\subsection{Participants}

The sample of this study included 632 women recruited from the general population, with a mean age of $28.26(S D=11.01)$ and $13.97(S D=3.07)$ years of education. Participants' Body Mass Index (BMI) ranged from 15.62 to $44.98 \mathrm{Kg} / \mathrm{m} 2$, with a mean of 22.67 ( $\mathrm{SD}=3.52$; range $=29.36$ ), which corresponds to normal weight values (BMI ranging from 18.5 to 24.9; WHO, 1995) [37]. Also, the sample's BMI distribution showed to be equivalent to the female Portuguese population's BMI distribution [38].

Before answering the self-report questionnaires (described below), participants completed an initial series of queries regarding demographic information (e.g., gender, age and education level), and current weight and height, posteriorly used to calculate BMI.

Early Memories of Warmth and Safeness Scale - Peers version (EMWSS_peers) [39]; The EMWSS_peers is a self-report questionnaire, with 12 items, adapted from the EMWSS [4], that aims at measuring the recall of peer-related positive early emotional and relational memories. Participants are asked to select the frequency of emotional experiences characterized by warmth, care, safeness, soothing and positive affection in their relationship

with peers (e.g., "I felt safe and secure with my peers/friends" or "I felt part of the peer group that I valued"), using a 5-point Likert scale ( $0=$ "No, Never" to $4=$ "Yes, Most of the time"). 
This scale showed good psychometric properties and excellent internal consistency $(\alpha=97)$. In the current study, the Cronbach's alpha was .97.

Other as Shamer Scale (OAS) [40, 41]; OAS is a 18-item self-report instrument that aims to assess external shame, that is, the perception that others see the self negatively (as inferior, inadequate or unattractive). The response options are displayed on a 5-point Likert scale $(0=$ Never to $4=$ Almost always), in which the respondents indicate the frequency of their perceptions about others' negative evaluations (e.g., "Other people see me as defective as a person"). Higher results in this measure are indicator of higher levels of external shame. The OAS's internal consistency revealed to be high both in the original version $(\alpha=.92)$ and in the Portuguese validation study $(\alpha=.91)$. The alpha value for this study was .93.

Self-Compassion Scale (SELFC) [32, 42]; The SELFC is a self-report scale composed of 26 items, designed to measure self-compassion through two key components: a positive one, which includes self-kindness, common humanity, and mindfulness; and a negative one, comprising self-judgment (e.g., "'I'm disapproving and judgmental about my own flaws and inadequacies”), isolation (e.g., "When I think about my inadequacies, it tends to make me feel more separate and cut off from the rest of the world'"), and over-identification (e.g., "When I fail at something important to me I become consumed by feeling of inadequacy"). According to the purpose of this study, only the composite measure of the 3 negative dimensions of the SCS was used, and defined as a self-judgment dimension. This scale has shown good reliabilities in the original version $(\alpha=.92)$ and in the Portuguese version $(\alpha=.89)$; concerning the current study, the Cronbach's alpha was .92 .

Eating Disorder Examination Questionnaire (EDE-Q) [43, 44]; The EDE-Q is a 36items self-report scale which evaluates the frequency and intensity of characteristic attitudes and behaviours of eating disorders. It consists of four subscales: restraint, weight concern, 
shape concern and eating concern. The items are rated for frequency of occurrence (items 115 , on a scale ranging from $0=$ "None" and $6=$ "Every day") or for severity (items 29-36, on a scale ranging from $0=$ "None" and $6=$ "Extremely"). This measure has shown an excellent internal consistency, in both the original and the Portuguese versions $(\alpha=.94)$. The current study used the global score of the EDE-Q (obtained through the calculation of the average of the four subscales), which presented a Cronbach's alpha of .92.

\subsection{Procedures}

The current study is part of a wider Portuguese research about the impact of different factors and emotion regulation processes on quality of life and eating psychopathology.

The present study's procedures respected all ethical and deontological requirements inherent to scientific research: the institution's boards approved the research protocol, participants were clarified about the purpose and procedures of the study, data confidentiality and voluntary nature of their participation. Also, participants were asked to provide their written informed consent previously to the administration of self-report measures.

Participants were recruited from several high education institutions, private companies and retail services, and the questionnaires were completed in its Portuguese version during a break authorized by their institutions' boards, in the presence of one of the researchers.

The original sample consisted of 921 individuals of both genders (232 men and 688 women), with ages ranging from 18 to 68 years old. However, taking into account the aims of this study, only 632 women, with ages ranging from 18 to 60 years old, were selected. The data cleaning procedure excluded: (a) male participants; (b) participants older than 60 years old and (c) cases in which more than $15 \%$ of the questionnaire's responses were missing. 


\subsection{Data Analysis}

Data analyses were conducted using the software IBM SPSS Statistics 22.0 (SPSS IBM; Chicago, IL), and the software AMOS was used to perform a path analysis [45].

Descriptive statistics were explored (means and standard deviations), in order to analyse the characteristics of the final sample. Then, Pearson product-moment correlations were performed [46] and coefficients were analysed in order to explore the relationships established between early affiliative memories of warmth and safeness with peers (EMWSS_peers), external shame (OAS), self-judgment (SJ) and disordered eating attitudes and behaviours (EDE-Q).

Finally, a path analysis was performed to examine whether early memories of warmth and safeness with peers would predict disordered eating attitudes and behaviours, through the mechanisms of external shame and self-judgment.

Peer-related early memories of warmth and safeness were considered as exogenous variables; external shame and self-judgment were hypothesized as mediator variables, and the global score of EDE-Q was entered as an endogenous variable. The estimation of the regression coefficients and fit statistics used the Maximum Likelihood method, and a set of goodness-offit indices were calculated in order to examine the adequacy of the model to the empirical data (e.g., CMIN/DF, CFI, TLI, RMSEA) [47]. Resorting to the Bootstrap resampling procedure, the significance of the paths was also examined, with 5000 samples, and $95 \%$ bias-corrected confidence intervals (CI) around the standardized estimates of total, direct and indirect effects. Effects with $p$ values under .050 were considered statistically significant.

\section{Results}

\subsection{Preliminary analyses}


The assumption of the normality of the distribution of the variables in study was confirmed by the analysis of Skewness (Sk) and Kurtosis $(\mathrm{Ku})$ values [48]. The skewness values ranged from -.99 to 1.09 , while the values of Kurtosis ranged from -.32 to .93 .

Additionally, preliminary analyses demonstrated that data followed the assumptions of linearity, normality, homocedasticity, independence of errors and multicolinearity among the variables [49].

\subsection{Descriptive and Correlations analyses}

The mean, standard deviations and Pearson product-moment correlation coefficients of the studied variables, for the total sample $(N=632)$, are reported in Table 1. Participants' EDE-Q values $(\mathrm{M}=1.25 ; \mathrm{SD}=1.12 ;$ Range $=5.13)$ fitted into the normative values for community samples $(\mathrm{M}=1.59 ; \mathrm{DP}=1.32 ;[50])$.

Results showed that positive early affiliative memories with peers (EMWSS_peers) were significantly, negatively, and moderately associated with external shame (OAS) and selfjudgment (SJ). Also, EMWSS_peers presented negative associations with the global score of

EDE-Q. Furthermore, results demonstrated that external shame presented a positive and strong correlation with self-judgment, and a moderate association with EDE-Q. Also, a positive and moderate relationship was found between self-judgment and EDE-Q.

Additionally, a partial correlation analysis, controlling for age and BMI, was performed. Results demonstrated that both the direction and magnitude of the variables' correlations remained similar, and therefore age and BMI were not included in later analysis.

Table 1

Means (M), Standard Deviations (SD), and Intercorrelation scores on self-report measures $(N=632)$ 


\begin{tabular}{lcccccc}
\hline Measures & M & SD & $\mathbf{1}$ & $\mathbf{2}$ & $\mathbf{3}$ & $\mathbf{4}$ \\
\hline 1. EMWSS_peers & 35.55 & 9.80 & 1 & - & - & - \\
2. OAS & 21.08 & 11.24 & $-.45^{* * *}$ & 1 & - & - \\
3. SCS_Self_judgment & 2.83 & .76 & $-.35^{* * *}$ & $.60^{* * *}$ & 1 & - \\
4. EDE_Q & 1.25 & 1.12 & $-.23^{* * *}$ & $.42^{* * *}$ & $.41^{* * *}$ & 1 \\
\hline
\end{tabular}

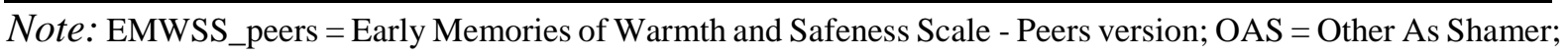

SCS_Self_judgment $=$ Self-Judgment dimension of SCS; EDE_Q = Eating Disorder Examination Questionnaire $* * * p<.001$

\subsection{Path analysis}

The purpose of this path analysis was to test the roles played by external shame and self-judgment in the association between early affiliative memories of warmth and safeness with peers and disordered eating attitudes and behaviours.

Initially, the tested model was saturated (i.e., with zero degrees of freedom), which comprised 13 parameters and explained $22 \%$ of the eating psychopathology's variance (EDEQ). In this model, one path was not significant: the direct effect of early affiliative memories of warmth and safeness with peers on EDE-Q ( $b_{\text {EMwss_peers }}=-.003 ; S E_{\mathrm{b}}=.005 ; Z=-.753 ; p=$ .601). In accordance with this result, this path was eliminated. The model was recalculated and results indicated that all path coefficients were statistically significant $(p<.050)$.

The final adjusted model presented an excellent model fit, with a non-significant Chisquare $\left[\mathrm{X}^{2}(1)=.567 ; p=.451\right]$. Different well-known and recommended fit indices were also analysed (Kline, 2005) and revealed an excellent fit to the empirical data $(\mathrm{CMIN} / \mathrm{DF}=.567$; $\mathrm{CFI}=1.000 ; \mathrm{TLI}=1.004 ; \mathrm{RMSEA}=.000 ;[\mathrm{IC}=.000-.095 ; p=.790])[46]$.

The final model (Figure 1) explained $22 \%$ of the variability of eating psychopathology (EDE-Q). Simultaneously, EMWSS_peers accounted for $20 \%$ of external shame; and $37 \%$ of 
self-judgment was explained by the direct effect of EMWSS_peers and its indirect effect through external shame.

More specifically, early memories of warmth and safeness with peers presented a direct effect of $-.45\left(b_{\text {Емwss_pers }}=-.514 ; S E b=.041 ; Z=-12.576 ; p<.001\right)$ on external shame and of -.10 $\left(b_{\text {EMwsS_pers }}=-.007 ; S E b=.003 ; Z=-2.719 ; p=.007\right)$ on self-judgment. In turn, external shame had a direct effect of $.56\left(b_{\mathrm{OAS}}=.038 ; S E b=.002 ; Z=15.900 ; p<.001\right)$ on self-judgment and of $.27\left(b_{\mathrm{OAS}}=.027 ; S E_{b}=.004 ; Z=6.092 ; p=<.001\right)$ on EDE-Q. It was also verified that selfjudgment had a direct effect of $.25\left(b_{\text {self judgment }}=.368 ; S E_{b}=.066 ; Z=5.613 ; p<.001\right)$ on eating psychopathology.

The analysis of the indirect effects indicated that early memories of warmth and safeness with peers presented indirect effects on EDE-Q, of $-.21(95 \% \mathrm{CI}=-.27--.15)$, which were totally explained by external shame and by self-judgment. Results also demonstrated that external shame presented an indirect effect of $.14(95 \%$ IC $=.09-.20)$ on eating psychopathology, which was partially carried by self-judgment. Overall, the tested model accounted for $22 \%$ of EDE-Q, and revealed that the impact of early memories of warmth and safeness with peers on eating psychopathology was fully carried by external shame and selfjudgment.

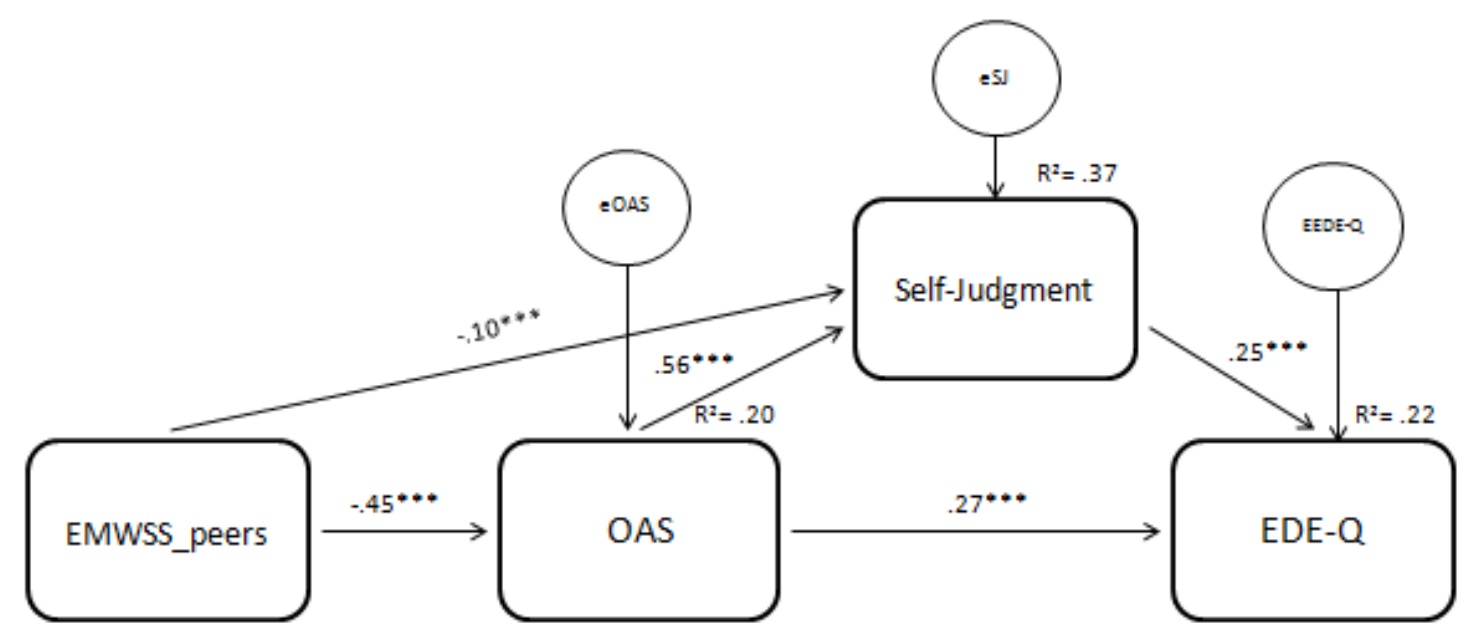


Figure 1. Final path model. Note: Standardized path coefficients among variables are presented. All path coefficients are significant at the .05 level; ***p $<.001$ EMWSS_peers = Early Memories of Warmth and Safeness Scale - Peer version; OAS $=$ Other As Shamer; Self-Judgment - Self-Judgment dimension of SCS; EDE_Q = Eating Disorder Examination Questionnaire.

\section{Discussion}

In accordance with previous literature, the recall of early positive memories is associated with the adoption of adaptive emotional strategies, which enhance the ability to deal with stressful events and demanding contexts [e.g., 17]. Also, recent research shed light on the key role of negative emotional memories on self-identity and life story [14], operating as threatactivating memories associated with experiences of shame and a series of maladaptive emotional processes [21, 22]. Although there are some evidences that suggest the role of painful early relational experiences in the engagement in disordered eating attitudes and behaviours $[34,35]$, the impact of early peer-related affiliative memories on eating psychopathology remains scarcely investigated. Therefore, the present study aimed to clarify the impact of early emotional memories with peers, characterized by warmth and safeness, on the engagement in disordered eating attitudes and behaviours.

In the current study, a path model explored the pervasive effect of the scarcity of peerrelated positive memories on eating psychopathology, and also the roles played by shame and self-judgmental attitudes on this relationship, in a sample of 632 women from the community.

Results showed that early positive and secure memories with peers are linked to lower levels of external shame and self-judgmental attitudes, and also to lower disordered eating attitudes and behaviours. These findings support the relationship between the recall of early affiliative memories and psychopathological symptoms [e.g., 7, 19], and seem to extend previous research, revealing that scarcity of early positive memories involving peers are significantly associated with disordered eating. 
Moreover, the tested model explained $22 \%$ of the eating psychopathology's variance and revealed an excellent model fit. Results indicated that the lack of early affiliative memories of warmth and safeness with peers did not directly predict the engagement in disordered eating attitudes and behaviours. Indeed, results revealed that the effect of these early positive memories on eating psychopathology is fully carried by the mechanisms of external shame and self-judgment.

These findings seem to add interesting accounts by suggesting that the lack of positive memories with peers (friends and colleagues) may increase the experience of inferiority or inadequacy and the tendency to experience critical and judgmental responses towards the self, which are crucial mechanisms that lead to the adoption of disordered eating behaviour [e.g., $30,33]$. In fact, the present study suggests the importance of affiliative memories with peers on the later proneness to eating psychopathology, through the mechanisms of shame and selfjudgmental attitudes. However, several limitations should be noted. Firstly, the main limitation of the present study is its cross-sectional nature, which does not allow the inference of causal relationships between the variables. Future research should focus on longitudinal designs to determine the directions of the studied associations over time. Another limitation is the use of a sample only composed of women from the general population. Even though disordered eating behaviours are more prevalent in females, upcoming studies should investigate this model in male samples and explore gender differences. Also, future studies should explore our hypotheses in clinical samples, for example eating disorders and obese patients. Finally, another possible limitation concerns to the use of self-report measures that may be susceptible to biases and compromise the generalization of the data. Thus, future research should include other assessment methods (such as interviews), in order to confirm our findings.

In conclusion, the current data adds new insights on how the recall of peers-related affiliative memories operates in eating psychopathology. Our results seem to support the 
hypothesis that women who show a lack of early positive peers-related memories tend to perceived that others see them negatively (as inferior, undesirable, devalued and unattractive), and present a higher tendency to adopt harshly self-critical and judgmental attitudes, which may trigger defensive and pathological responses. In this line, findings suggest that disordered eating attitudes and behaviours (characterized by the rigid control over weight, body shape and eating) may emerge as strategies to assure social acceptance and to deal with a sense of inferiority and a judgmental self-to-self relationship. Furthermore, the present study seems to be an important contribution to clinical practice and to the development of intervention community programs. In fact, our findings suggest the relevance of dishaming strategies and the promotion of more adaptive emotional regulation processes (e.g., self-compassion), and offers relevant data that support the pertinence of the development of novel therapeutic approaches that addresses affect regulation difficulties, shame, self-directed hostility, namely based on compassion-focused therapy [20], for the treatment and prevention of disordered eating attitudes and behaviours, particularly in a context of early negative emotional and relational experiences involving peers.

\section{Compliance with ethical standards}

Ethical approval: All procedures performed in studies involving human participants were in accordance with the ethical standards of the institutional research committee and with the 1964 Helsinki declaration and its later amendments or comparable ethical standards.

Informed consent: Informed consent was obtained from all individual participants included in the study.

Conflict of interest: The authors of this manuscript declare no conflict of interest. 


\section{ORCID}

Ana Laura Mendes: orcid.org/0000-0002-9889-5855

Joana Marta-Simões: orcid.org/0000-0002-7807-8575

Cláudia Ferreira: orcid.org/0000-0002-7020-9606

\section{References}

1. Baumeister RF, Leary MR (1995) The need to belong: Desire for interpersonal attachments as a fundamental human motivation. Psychological Bulletin 117(3): 497- 529. doi: 10.1037/0033-2909.117.3.497

2. Bowlby J (1969) Attachment: Attachment and loss, Vol. 1. London, Hogarth Press.

3. Bowlby J (1973) Separation, Anxiety and Anger: Attachment and Loss, Vol. 2. London, Hogarth Press.

4. Richter A, Gilbert P, McEwan K (2009) Development of an early memories of warmth and safeness scale and its relationship to psychopathology. Psychology and Psychotherapy: Theory, Research and Practice 82: 171-184. doi: 10.1348/147608308X395213.

5. Gerhardt S (2004). Why Love Matters. How Affection Shapes a Baby’s Brain. London, Bruner-Routledge.

6. Schore AN (1994) Affect regulation and the origin of the self: The neurobiology of emotional development. Hillsdale NJ, Erlbaum.

7. DeHart T, Peham BW, Tennen H (2006) What lies beneath: Parenting style and implicit self-esteem. Journal of Experimental Social Psychology 42(1): 1-17. doi: 10.1016/j.jesp.2004.12.005.

8. Mikulincer M, Shaver RP (2004) Security-based self-representations in adulthood: Contents and processes. In: Rholes NS, Simpson JA (eds) Adult Attachment: Theory, research, and clinical implications. New York, Guilford, pp 159-195. 
9. Cheng H, Furnham A (2004) Perceived parental rearing style, self-esteem and self-criticism as predictors of happiness. Journal of Happiness Studies 5(1): 1-21.

10. Bifulco A, Moran P (1998) Wednesday's child: Research into women's experience of neglect and abuse in childhood, and adult depression. London, Routledge.

11. Gilbert P, Irons C (2008) Shame, self-criticism, and self-compassion in adolescence. In: Allan NB, Sheeber LB (eds) Adolescence Emotional Development and the Emergence of Depressive Disorders. London, Cambridge University Press, pp 195-214

12. Brewin C (2006) Understanding cognitive behaviour therapy: A retrieval competition account. Behaviour Research and Therapy 44(6): 765-784. doi: 10.1016/j.brat.2006.02.005

13. Gilbert P (2002) Body Shame: A Biopsychosocial Conceptualisation and Overview, with Treatment Implications. In: Gilbert P, Miles J (eds) Body Shame: Conceptualisation, Research and Treatment. London, Routledge, pp 3-54

14. Pinto Gouveia J, Matos M (2011) Can shame memories become a key to identity? The centrally of shame memories predicts psychopathology. Applied Cognitive Psychology 25: 281-290. doi: 10.1002/acp1689.

15. Mikulincer M, Shaver P (2005) Mental representation and attachment security. In: Baldwin MW (ed) Interpersonal cognition. New York, Guilford press, pp 233-266.

16. Gilbert P (1998) What is Shame? Some Core Issues and Controversies. In: Gilbert P, Andrews B (eds) Shem: Interpersonal Behaviour, Psychopathology and Culture. New York, Oxford University Press, pp 3-36.

17. Gilbert P, McEwan K, Matos M, Rivis A (2011) Fear of compassion: a study of psychological processes that block compassion. Psychology and Psychotherapy: Theory, Research and Practice 84: 239-255. doi: 10.1348/ 147608310X526511 
18. Matos M, Pinto-Gouveia J, Duarte C (2013) Internalizing early memories of shame and lack of safeness and warmth: the mediating role of shame on depression. Behavioral Cognitive Psychotherapy 41(4): 479-93. doi: 10.1017/S1352465812001099

19. Gilbert P (2003) Evolution, Social Roles and the Differences in Shame and Guilt, Social Research 70(4): 1205-1230

20. Gilbert P (2005) Compassion and cruelty: A biopsychosocial approach. In: Gilbert P (ed) Compassion: Conceptualisation, research and use in psychotherapy. London, Routledge, pp 9-74.

21. Cunha M, Matos M, Faria D, Zagalo S (2012) Shame memories and psychopathology in adolescence: the mediator effect of shame. International Journal of Psychology and Psychological Therapy 12(2): 203-218.

22. Murray C, Waller G, Legg C (2000) Family dysfunction and bulimic psychopathology: The mediating role of shame. International Journal of Eating Disorders 28(1): 84-89. doi: 10.1002/(SICI)1098-108X(200007)28:1<84::AID-EAT10>3.0.CO;2-R.

23. Tangney JP, Dearing RL (2002) Shame and Guilt. New York, Guilford Press.

24. Lewis M (1992) Shame: The exposed self. New York, The Free Press.

25. Gilbert P (2007) The evolution of shame as a marker for relationship security: a biopsychosocial approach. In: Tracy J, Robin R, Tangney J (eds) The self- conscious emotions: theory and research. New York, Guilford, pp 283-309.

26. Kim S, Thibodeau R, Jorgensen R (2011) Shame, guilt, and depressive symptoms: a metaanalytic review. Psychological Bulletin 137: 68-96.

27. Ferreira C, Pinto Gouveia J, Duarte C (2013) Drive for thinness as a women's strategy to avoid inferiority. International Journal of Psychology and Psychological Therapy 13(1): 15- 29. 
28. Gee A, Troop NN (2003) Shame, depressive symptoms and eating weight and shape concerns in a nonclinical sample. Eating and Weight Disorders 8(1): 72-75. doi: 10.1007/BF03324992

29. Grabhorn R, Stenner H, Stangier U, Kaufhold J (2006) Social anxiety in anorexia and bulimia nervosa: The mediating role of shame. Clinical Psychology and Psychotherapy 13(1): 12-19. doi: 10.1002/cpp.463

30. Pinto-Gouveia J, Ferreira C, Duarte C (2014) Thinness in the pursuit for social safeness: an integrative model of social rank mentality to explain eating psychopathology. Clinical psychology and psychotherapy 21(2): 154 - 165. doi: 10.1002/cpp.1820

31. Gilbert P, Irons C (2005) Focused therapies and compassionate mind training for shame and self-attacking. In: Gilbert P (ed) Compassion: Conceptualizations, research and use in psychotherapy, London, Routledge, pp 263-325.

32. Neff KD (2003) The development and Validation of a scale to measure self-compassion. Self and Identity 2(3): 223-250.doi: 10.1080/15298860390209035

33. Bellew R, Gilbert P, Mills A, McEwan K, Gale C (2006) Eating attitudes and striving to avoid inferiority. Eating Disorders 14: 313-322. doi:10.1080/10640260600796242

34. Keith L, Gillanders D, Simpson S (2009) An Exploration of the Main Sources of Shame in an Eating-Disordered Population. Clinical Psychology and Psychotherapy 16: 317-327. doi: $10.1002 /$ cpp.629.

35. Van den Berg P, Wertheim EH, Thompson JK, Paxton SJ (2002) Development of body image, eating disturbance, and general psychological functioning in adolescent females: A replication using covariance structure modeling in an Australian sample. International Journal of Eating Disorders 32: 46-51. 
36. Matos M, Pinto-Gouveia J (2014) Shamed by a parent or by others: The role of attachment in shame memories relation to depression. International Journal of Psychology and Psychological Therapy 14(2): 217-244.

37. WHO (1995) Physical status: the use and interpretation of anthropometry. Reports of a WHO Expert Committee. WHO Technical Report series 854. Geneva, World Health Organization

38. Poínhos R, Franchini B, Afonso C, Correia F, Teixeira VH, Moreira P, Durão C, Pinho O, Silva D, Lima Reis JP, Veríssimo T, de Almeida MDV (2009) Alimentação e estilos de vida da população Portuguesa: metodologia e resultados) preliminares [Alimentation and life styles of the Portuguese population: methodology and preliminary results]. Alimentação Humana 15(3): 43-60.

39. Ferreira C, Matos M, Cunha M, Duarte C, Pinto-Gouveia J (2015) Development and validation studies of early memories of warmth and safeness with peers. Manuscript in preparation.

40. Goss K, Gilbert P, Allan S (1994) An exploration of shame measures: I: The 'other as shamer'scale. Personality and Individual Differences 17(5): 713-717. doi: 10.1016/01918869(94)90149-X

41. Matos M, Pinto-Gouveia J, Duarte C (2011) Other as Shamer: Versão Portuguesa e propriedades psicométricas de uma medida de vergonha externa. Manuscript submitted for publication.

42. Castilho P, Pinto-Gouveia J (2011) Autocompaixão: Estudo de validação da versão portuguesa da Escala de Autocompaixão e da sua relação com as experiências adversas da infância, a comparação social e a psicopatologia. Psychologica 54: 203- 230. 
43. Fairburn CG, Beglin SJ (1994) Assessment of eating disorders: Interview of self-report questionnaire? International Journal of Eating Disorders 16(4): 363-370. doi: 10.1002/1098-108X(199412).

44. Machado PP, Martins C, Vaz AR, Conceição E, Bastos AP, Gonçalves S (2014) Eating disorder Examination questionnaire: psychometric properties and norms for the Portuguese population. European Eating Disorders Review 22(6): 448-453. doi:10.1002/erv.2318.

45. Arbuckle JL (2006) Amos (Version 7.0) [Computer Program]. Chicago: SPSS.

46. Cohen J, Cohen P, West S G, Aiken LS (2003) Applied multiple regression/correlation analysis for the behavioral sciences (3rd ed.). Hillsdale, Erlbaum.

47. Hu L, Bentler P (1999) Cutoff Criteria for Fit Indexes in Covariance Structure Analysis: Conventional Criteria Versus New Alternatives. Structural Equation Modeling 6(1): 1-55.

48. Kline RB (2005) Principles and Practice of Structural Equation Modeling (2nd ed.). New York, The Guilford Press.

49. Field A (2004) Discovering statistics using SPSS (3th ed.). London, Sage Publications.

50. Luce KH, Crowther JH, Pole M (2008) Eating Disorder Examination Questionnaire (EDEQ): norms for undergraduate women. International Journal of Eating Disorders 41(3): 273176. doi: 10.1002/eat.20504 